\title{
A Robótica Sustentável como Estratégia no Ensino de Ciências
}

Maria do Carmo Santos Rocha*, Aparecida da Silva Xavier Barros ${ }^{\star \star}$, Petterson Santos Rocha*** Bruno Xavier Barros ${ }^{\star * \star *}$, Déric Vinícius Santos ${ }^{\star \star \star * *}$

\section{Resumo}

Este artigo apresenta uma oficina de robótica sustentável voltada para o ensino de Ciências nas séries finais do Ensino Fundamental, na qual os docentes participantes, além de poderem aprofundar seus conhecimentos acerca da construção de robôs e outros mecanismos, puderam refletir sobre os temas sustentabilidade e preservação do meio ambiente. A oficina abordou temas como mecânica, movimento e energia. Por conta da pandemia, essa atividade foi ministrada de forma remota. Os resultados mostram que é possível dinamizar as aulas de Ciências e promover várias aprendizagens utilizando recursos disponíveis na escola, como materiais de sucata, recicláveis ou reutilizáveis.

Palavras-chave: Robótica Sustentável, Ensino de Ciências, Oficina.

\section{Introdução}

A robótica tem conquistado cada vez mais o interesse de diversos setores, especialmente o setor da educação (FUNDAÇÃO TELEFÔNICA VIVO, 2021), sendo aplicada desde o Ensino Fundamental até o Ensino Superior. No âmbito pedagógico, a robótica tem sido apontada como uma possibilidade de aumentar o envolvimento

* Graduada em Pedagogia pela Universidade de Pernambuco (UPE). Professora da rede municipal de Camocim de São Félix e Analista em Gestão Educacional da rede estadual de Pernambuco, Brasil. E-mail: mcrocha16@ hotmail.com

** Doutoranda em Educação Matemática e Tecnológica pela Universidade Federal de Pernambuco (UFPE). Professora do Instituto Federal da Paraíba (IFPB), Brasil. E-mail: aparecidaxbarros@hotmail.com

*** Graduando em Matemática pela Universidade Federal de Pernambuco (UFPE), Brasil. E-mail: pettersonrocha18@ gmail.com

**** Graduando em Engenharia Elétrica pela Universidade Federal de Pernambuco (UFPE), Brasil. E-mail: brunoxb2009@ gmail.com

${ }^{* * * *}$ Graduando em Matemática pela Universidade Federal de Pernambuco (UFPE), Brasil. E-mail: dericvinicius10@ gmail.com

https://10.5335/rbecm.v5iespecial.12875

http://creativecommons.org/licenses/by-nc-nd/4.0

ISSN: 2595-7376 
dos alunos no processo de aprendizagem, uma vez que tem como objetivo levá-los "a questionar, pensar e procurar soluções, a sair da teoria para a prática usando ensinamentos obtidos em sala de aula, na vivência cotidiana, nos relacionamentos, nos conceitos e valores" (NASCIMENTO, 2015, p. 2).

Por outro lado, levando em consideração a realidade de muitas escolas públicas brasileiras, várias iniciativas relacionadas à robótica educacional acabam não sendo integradas aos conteúdos das propostas pedagógicas ou sendo aplicadas de forma limitada por conta da falta de conhecimento aprofundado, recursos de infraestrutura, técnico e de formação de professores (FUNDAÇÃO TELEFÔNICA VIVO, 2020). Nessas escolas, portanto, a robótica ainda continua a ser percebida por professores e estudantes como algo que está distante da sua realidade.

Foi pensando nisso que buscou-se desenvolver uma oficina de robótica voltada para o ensino de Ciências nas séries finais do Ensino Fundamental, na qual os participantes, professores da rede pública, além de poderem aprofundar seus conhecimentos no que se refere à robótica sustentável e de baixo custo, com uso de materiais de sucata, recicláveis ou reutilizáveis para a construção de robôs e outros mecanismos, puderam refletir sobre temas como sustentabilidade e preservação do meio ambiente.

A oficina em tela está alinhada à Base Nacional Comum Curricular (BNCC) e foi produzida a partir de estudos bibliográficos, tendo como principais aportes teóricos os estudos de Papert (1986; 2007) e Medeiros, Wunsch e Bottentuit Junior (2019). Nesse sentido, pretendeu-se estabeler uma conexão entre a BNCC e a robótica educacional para auxiliar o professor, que é um agente essencial para auxiliar os alunos no desenvolvimento de competências que lhes permitam utilizar os saberes que adquirirem para dar conta das atividades do seu dia a dia e fazer escolhas e intervenções conscientes, pautadas no respeito a princípios universais, como a ética, os direitos humanos, a justiça social e a sustentabilidade ambiental (BRASIL, 2018).

A proposta metodológica desta oficina une o estudo dos princípios básicos da robótica educacional sustentável e de baixo custo com o levantamento de boas práticas pedagógicas que possam ser replicadas, adaptadas e recriadas. Sendo assim, na segunda e terceira seções são descritos alguns aspectos teóricos relacionados ao tema da oficina. Na quarta seção, é exposta a proposta de oficina e, na quinta seção, é apresentada a discussão dos resultados mais relevantes. Na sequência, são trazidas as considerações finais deste trabalho. 


\section{A robótica educacional sustentável e de baixo custo}

A robótica na educação teve o seu início na década de 1980, com o advento da informática no contexto escolar, especialmente a partir das pesquisas de Seymour Papert sobre a linguagem de programação LOGO. Um dos trabalhos mais conhecidos de Papert foi a criação da "tartaruga" controlada em LOGO (ALMEIDA; SILVA; AMARAL, 2013), "um dispositivo físico que desenhava no solo as figuras geométricas. Apenas com o surgimento dos computadores pessoais é que a tartaruga deu lugar a um cursor virtual, dentro de um ambiente de programação" (MEDEIROS; WUNSCH; BOTTENTUIT JUNIOR, 2019, p. 4).

Papert $(1986$; 2007) compreende a tecnologia como algo que atrai as crianças e com isso facilita os processos de ensino e aprendizagem. O estudioso também concorda com Piaget (1976) quando este afirmou que a criança é um "ser pensante" e construtora de suas próprias estruturas cognitivas, mesmo sem ser ensinada. Nesse sentido, segundo Papert, criador do Construcionismo, uma reconstrução teórica a partir do construtivismo piagetiano, é preciso "ensinar, de forma a produzir o máximo de aprendizagem, com o mínimo de ensino" (NUNES; SANTOS, 2013, p. 2).

Sobre o campo de estudos da Robótica Educacional, Baldow e Leão (2017, p. 2) afirmam que alguns autores o separam em duas categorias: "a primeira baseada no uso de kits de robótica comerciais e a segunda que trabalha com o reaproveitamento de equipamentos em desuso". Assim sendo, a robótica sustentável pode ser conceituada como sendo "a bricolagem de materiais de baixo custo e sucata, em combinação com módulos de automação e controle, visando à produção de autômatos e robôs para uso pedagógico, tendo como pano de fundo a valorização do pensamento concreto na aprendizagem" (MEDEIROS; WUNSCH; BOTTENTUIT JUNIOR, 2019, p. 7).

Nesse ponto, ainda pode-se afirmar também que o trabalho com a robótica sustentável colabora para a diminuição do impacto ambiental (BALDOW; LEÃO, 2017; FUNDAÇÃO TELEFÔNICA VIVO, 2021; MEDEIROS; WUNSCH; BOTTENTUIT JUNIOR, 2019), uma vez que propicia a reciclagem e a reutilização de materiais, assim como a abordagem de questões como o consumo consciente e o descarte correto dos resíduos, por exemplo. Notadamente, 
a preocupação com o lixo e o meio ambiente, a cada dia está aumentando por parte da sociedade, do governo e das instituições de ensino, que buscam conscientizar a população. Com o avanço da tecnologia, aumenta também a discussão sobre o descarte dos artefatos, tanto os que não funcionam, como os que funcionam, mas não servem mais aos usuários, no caso, os lixos eletrônicos (BALDOW; LEÃO, 2017, p. 700).

De acordo com Medeiros, Wunsch e Bottentuit Junior (2019), a abordagem da robótica sustentável perpassa por três dimensões, que possuem alguns fatores facilitadores, e emprega recursos variados, conforme sintetizamos na Figura 1.

Figura 1: Robótica sustentável: dimensões, fatores facilitadores e recursos empregados

- Tecnológica: relacionada aos recursos e técnicas necessários à construção de robôs;

- Social: relacionada à interação dos professores, alunos e comunidade;

- Ambiental: relacionada ao uso de materiais recicláveis e reutilizáveis e sua adequação às montagens dos robôs.

\section{Dimensões}

\section{Fatores} facilitadores

- Modularização;

- Plataformas abertas (open source);

- Diminuição do custo;

- Compartilhamento do

conhecimento;

- Uso de materiais

reutilizáveis.
- Módulos de controle e alimentação (ex. microprocessador, placas de controle de motores, suporte de pilhas e baterias);

- Materiais recicláveis (ex. palitos de picolé, tampas de plástico);

- Materiais reutilizáveis (ex. motores de acionadores de disquete e CD/DVD);

- Materiais para bricolagem em geral (ex.: cola, papel e EVA);

- Materiais manufaturados por demanda (ex. suportes, ornamentos, etc.)
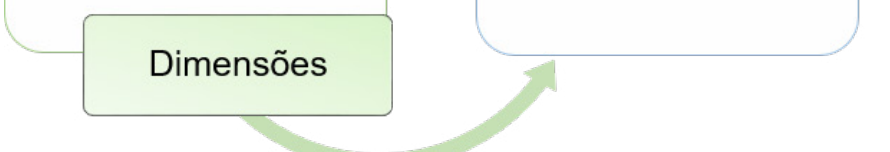

Recursos

Fonte: Os autores (2021), a partir de Medeiros, Wunsch e Bottentuit Junior (2019, p. 7-9).

Em síntese, pode-se afirmar que a utilização de novas tecnologias na educação, como a robótica educacional, é considerada uma estratégia atraente para o público das gerações $\mathrm{Z}^{1}$ e Alfa ${ }^{2}$ (TOLEDO, 2012), especialmente porque faz uso de ferramentas diferenciadas, que incentivam o protagonismo dos alunos. Se bem orientado, nesse processo "mão na massa", os alunos terão a oportunidade de desenvolver habilidades importantes para a vida contemporânea como a concentração, a cooperação, a organização, a criatividade, a observação, a criticidade, dentre outras (FUNDAÇÃO TELEFÔNICA VIVO, 2020). 
Dito isso, cabe ressaltar que a literatura tem documentado o crescente interesse da comunidade científica pelo uso da robótica no contexto de sala de aula, conforme pontuaram Raabe e Bombasar (2018) em uma revisão sistemática da literatura (RSL) sobre o uso de robótica na educação básica pública brasileira. Os autores analisaram 31 artigos, publicados entre 2013 e 2017, e relataram que a maioria dos trabalhos teve como foco o apoio ao ensino de conteúdos das áreas da Computação e Matemática para públicos do Ensino Fundamental, com o uso de kits Lego e Arduino. Foram identificadas também as seguintes lacunas de pesquisa: escassez de trabalhos em robótica na Educação Infantil; pouca diversidade de conteúdos explorados, tendo em vista que a maioria dos estudos focalizou o apoio ao ensino de conteúdos que são próximos ao campo da robótica enquanto ciência, carecendo, portanto, de mais projetos/estudos multi e interdisciplinares; predominância de investigações qualitativas; e reduzida integração curricular, considerando-se que a maioria dos estudos analisados realizou uma intervenção de curta duração e com grupos reduzidos de alunos.

Brito (2019) realizou um Mapeamento Sistemático de Literatura (MSL) na Biblioteca Digital Brasileira de Teses e Dissertações (BDTD) acerca da produção científica publicada no período referente a $1^{\circ}$ de janeiro de 2001 e 31 de dezembro de 2017. Dentre as 48 pesquisas encontradas, $85 \%$ eram dissertações de mestrado e $15 \%$ teses de doutorado. Os estados que mais se destacaram na produção de trabalhos foram: São Paulo, Rio Grande do Sul, Amazonas, Rio Grande do Norte e Paraíba. Em relação às instituições pesquisadoras, 22 instituições vêm trabalhando na área e $86 \%$ delas são públicas, sendo as maiores produtoras de pesquisas: a UFRN, a UEPB, a UFRGS, a USP, a PUC-SP e a UFAM, que juntas foram responsáveis por $47,92 \%$ do total da amostra. Foram identificados 29 campos teóricos-conceituais que fundamentaram as pesquisas analisadas, sendo os mais citados: o Construcionismo, o Construtivismo, a relação entre Tecnologia e Educação, Inteligência Artificial e Sociointeracionismo. A investigação ainda revelou que: dos 37 trabalhos realizados em contexto escolar, nenhum teve como foco a Educação Infantil; em 41,67\% dos trabalhos da amostra foram utilizados kits da marca LEGO e 25\% utilizaram a Robótica Pedagógica Livre ${ }^{3}$.

Dentre os estudos que contribuem para a aplicação da robótica sustentável e de baixo custo, foi identificado o trabalho de Celinski et al. (2012), no qual foi relatado o desenvolvimento de oficinas sobre robótica utilizando o lixo eletrônico. As atividades, executadas a partir de um Programa de Extensão, abordaram a questão 
do descarte consciente do lixo eletrônico e a viabilidade do reuso de partes deste material em oficinas de robótica educativa de baixo custo a serem realizadas em escolas públicas. Como resultados desta proposta foram desenvolvidos dois protótipos de artefatos robóticos a fim de complementar os conhecimentos sobre Matemática, Física, Biologia, Design e Artes.

No trabalho de Bogarim, Larrea e Ghinozzi (2015), por sua vez, foram reutilizados componentes de computadores descartados com o objetivo oferecer manutenção em computadores de escolas públicas do município, diminuindo, assim, o custo das escolas com a compra de novos componentes e evitando que os computadores deixassem de ser utilizados pelos alunos. Os integrantes do projeto também ministraram uma série de palestras nas escolas, nas quais orientaram sobre o descarte consciente e a gravidade do lixo eletrônico para a saúde e a natureza.

Em um trabalho mais recente, Silva et al. (2020) apresentaram uma experiência de robótica educacional utilizando lixo eletrônico como recurso didático para ensinar conceitos de eletricidade aos alunos do Ensino Fundamental. Os resultados mostraram que a proposta foi positiva, possibilitando a aprendizagem de conteúdos como, por exemplo, potência elétrica, corrente elétrica, resistência elétrica e interação matéria/energia.

\section{Conexões entre a BNCC e a robótica educacional sustentável e de baixo custo}

A BNCC, que é uma referência para a construção dos currículos de todas as escolas brasileiras, foi elaborada estabelecendo como pilares dez competências ${ }^{4}$ gerais que devem nortear o trabalho educativo em todos os componentes curriculares $^{5}$. Nesse caso, essas competências "inter-relacionam-se e desdobram-se no tratamento didático proposto para as três etapas da Educação Básica (Educação Infantil, Ensino Fundamental e Ensino Médio)" (BRASIL, 2018, p. 8-9), não sendo necessário, portanto, que os professores planejem aulas específicas sobre elas, mas propiciem a sua aprendizagem de forma articulada à de outras aprendizagens dos componentes curriculares com os quais trabalham.

Compreende-se, então, que as aprendizagens das competências gerais da BNCC se articulam e potencializam aprendizagens envolvendo a robótica educacional, como na competência 1 , que trata da valorização e utilização dos conhecimentos 
historicamente construídos, espera-se, por exemplo, que os alunos se apropriem do processo de construção do conhecimento, demonstrem motivação e autonomia para aprender, utilizem o conhecimento para solucionar problemas diversos, compartilhem informações com os colegas, construam coletivamente o conhecimento.

$\mathrm{Na}$ competência 2, que trata do exercício da curiosidade intelectual e do uso de estratégias próprias das ciências, dentre as quais a investigação, a reflexão, a análise crítica, a imaginação e a criatividade, espera-se, por exemplo, que os alunos busquem soluções criativas e inovadoras, assim como reflitam sobre aquilo que constroem.

Na competência 3, que trata da valorização e fruição das diversas manifestações artísticas e culturais, das locais às mundiais, e também da participação dos alunos em práticas diversificadas da produção artístico-cultural, a partir do componente Artes, por exemplo, os alunos podem adentrar em cenários antigos e descobrir que há muito tempo já se construíam robôs. "Leonardo da Vinci, grande artista e inventor genial, usando a imaginação, inventividade e conhecimentos matemáticos e físicos, desenvolveu máquinas fantásticas - verdadeiros robôs - para executar tarefas complexas ou perigosas" (FUNDAÇÃO TELEFÔNICA VIVO, 2020, p. 180).

$\mathrm{Na}$ competência 4, que trata da utilização de diferentes linguagens, espera-se, por exemplo, que os alunos adquiram a capacidade de: comunicar-se de forma verbal, textual, corporal, artística e científica; ouvir outras pessoas com atenção, interesse e respeito; expressar suas ideias, opiniões, emoções e sentimentos com clareza; estabelecer conexões com as falas de outras pessoas, visando encontrar o entendimento mútuo.

Na competência 5, que trata da compreensão, utilização e criação de tecnologias digitais de informação e comunicação, evidencia-se o reconhecimento do papel fundamental da tecnologia e espera-se que os alunos façam um uso qualificado e ético das diversas ferramentas existentes. A cultura maker $^{6}$ e a robótica se inserem nesse contexto de forma muito significativa.

Na competência 6, que trata da apropriação de conhecimentos e experiências que possibilitem aos alunos entender as relações próprias do mundo do trabalho e fazer escolhas alinhadas ao exercício da cidadania e ao seu projeto de vida, abre-se espaço para, de acordo com as particularidades de cada componente curricular, despertar nesses sujeitos o interesse e a admiração por determinada profissão ou prática.

Na competência 7, que trata da argumentação com base em fatos, dados e informações confiáveis, espera-se, por exemplo, que os alunos se tornem capazes de 
formular, negociar e defender suas ideias, pontos de vista e decisões comuns, de forma ética em relação ao cuidado de si mesmo, dos outros e do planeta. Destaca-se aqui, no âmbito do desenvolvimento de projetos de robótica sustentável, a importância de que os alunos compreendam a importância do meio ambiente para a sobrevivência da humanidade e do planeta e busquem engajar-se no desenvolvimento de ações positivas para a promoção da sustentabilidade ambiental.

Na competência 8, que trata do aprendizado que crianças e jovens devem adquirir a respeito de si mesmos, espera-se, por exemplo, que esses sujeitos se percebam capazes de resolver problemas, mesmo que em ritmos diferentes, que fiquem atentos aos estímulos que distraem ou desviam a sua atenção, que usem seus conhecimentos, habilidades e atitudes com tranquilidade e otimismo.

Na competência 9, que trata do exercício da empatia, do diálogo, da resolução de conflitos e da cooperação, espera-se, por exemplo, que os alunos construam, negociem e respeitem normas de convivência, que tenham o entendimento do papel e da importância do outro no grupo, que procurem fazer-se respeitar e promovam o respeito ao outro.

Na competência 10, que trata do agir pessoal e coletivo de maneira responsável e cidadã, espera-se, por exemplo, que os alunos posicionem-se em relação a direitos e responsabilidades, indo além de seus interesses pessoais, assim como decidam sobre questões que afetam a todos com base em princípios éticos, democráticos, inclusivos, sustentáveis e democráticos.

\section{A proposta de oficina sobre robótica educacional sustentável e de baixo custo}

Inicialmente, o grupo que idealizou a proposta contatou individualmente os participantes, que são colegas de trabalho de uma das formadoras. A oficina, que teve carga horária total de $4 \mathrm{~h}$, ocorreu através do Google Meet, por conta da suspensão das atividades presenciais nas escolas estaduais pernambucanas, em quatro seções de $1 \mathrm{~h}$ cada, em datas previamente acordadas com os participantes: cinco professores de Ciências atuantes em turmas de $8^{\circ}$ e $9^{\circ}$ anos do Ensino Fundamental.

A pequena carga horária é justificada porque os professores relataram falta de tempo para a formação, uma vez que também eram responsáveis por outras 
atividades, como, por exemplo: aulas remotas, reuniões online, contato pelas redes sociais com as famílias dos alunos etc.

O Quadro 1 foi elaborado para apresentar o desenvolvimento da oficina.

Quadro 1: Etapas da Oficina de Robótica

\begin{tabular}{|l|l|l|}
\hline \multicolumn{1}{|c|}{ Conteúdos } & \multicolumn{1}{|c|}{ Atividades } & \multicolumn{1}{c|}{ Meses } \\
\hline \multirow{2}{*}{$\begin{array}{l}\text { Robótica na Educação; } \\
\text { Robótica Sustentável. }\end{array}$} & $\begin{array}{l}\text { Apresentação de vídeos para inspirar os par- } \\
\text { ticipantes (por conta do tempo os vídeos não } \\
\text { foram exibidos na íntegra). }\end{array}$ & \\
\cline { 2 - 3 } & $\begin{array}{l}\text { Leitura e discussão sobre o que é robótica } \\
\text { sustentável (a leitura dos textos foi feita pre- } \\
\text { viamente por cada participante, em horário } \\
\text { mais conveniente para ele/a); }\end{array}$ & \multirow{2}{*}{02 e 03/2021 } \\
\cline { 2 - 3 } & $\begin{array}{l}\text { Buscas guiadas de materiais de apoio na In- } \\
\text { ternet: projetos, artigos, livros, sites e blogs } \\
\text { que apresentam experiências sobre robótica } \\
\text { sustentável, dentre outros (as buscas tiveram } \\
\text { continuidade fora do horário da oficina. Nesse } \\
\text { caso, os participantes fizeram as pesquisas } \\
\text { individualmente). }\end{array}$ & \\
\hline $\begin{array}{l}\text { Bricolagem; } \\
\text { Desenvolvimento de habilidades } \\
\text { de montagem; }\end{array}$ & $\begin{array}{l}\text { Fesenvolvimento de atividades práticas (deta- } \\
\text { Formas geométricas planas; } \\
\text { Velocidade e movimento; Atrito. }\end{array}$ & Ihadas na próxima seção). \\
\hline
\end{tabular}

Fonte: Os autores (2021).

Como suporte à oficina foi ofertado aos participantes todo o conteúdo vivenciado em formato de texto com ilustrações e, também, orientações, uma vez que algumas atividades foram realizadas fora do horário reservado aos encontros. Na próxima seção, será mostrado como os participantes puderam por em prática os temas abordados, bem como a forma pela qual a oficina foi avaliada por eles/as.

\section{Resultados e discussão}

O primeiro encontro contemplou a apresentação de vídeos ${ }^{7}$ para inspirar os participantes e o estudo geral da temática da oficina "Robótica na Educação" e "Robótica Sustentável", o que implicou também na reflexão sobre a formação de professores para o uso da robótica. Como embasamento foi utilizado o texto "A 
robótica sustentável na educação: sucata e materiais elétricos como suporte para a formação do docente atual”, de Medeiros, Wunsch e Bottentuit Junior (2019), cuja leitura foi solicitada aos participantes previamente. Após as discussões sobre o texto, foram feitas buscas guiadas na Internet, visando colocar os docentes em contato com materiais e experiências sobre robótica educacional sustentável e de baixo custo. Foi solicitado aos participantes que registrassem as buscas.

No segundo encontro foram catalogadas as experiências que mais despertaram $o$ interesse do grupo, bem como externadas as dúvidas e feitos alguns esclarecimentos. Nesse momento, foi apresentada aos participantes a primeira proposta de carrinho robô, que está descrita no artigo de Medeiros, Wunsch e Bottentuit Junior (2019). O carrinho, montado com materiais recicláveis, é controlado por motores reutilizados e ligados a uma alimentação por pilhas e "auxilia na explicação de forma concreta dos conceitos de ação e reação da Dinâmica, além de vários conceitos correlatos, como ponto de equilíbrio, atrito, movimento em diferentes dimensões, dentro outros" (MEDEIROS; WUNSCH; BOTTENTUIT JUNIOR, 2019, p. 13).

Nos dois últimos encontros, foram apresentados outros protótipos: um carro movido a bexiga, um carro movido a ratoeira e um triciclo com motor elétrico (REVISTA NOVA ESCOLA, 2008 online). Todos os exemplares são bastante simples, sem agregação de módulos de hardware de controle como o Arduino, assim como sensores e atuadores. Nesse sentido, quando postos em ação, os carrinhos não conseguiam, por exemplo, se movimentar de forma autônoma nem desviar de obstáculos e ter controle de velocidade. Todavia, foram considerados muito valiosos pelo grupo, sendo muito úteis para iniciar o tratamento de conteúdos como mecânica, movimento e energia.

Ainda no último encontro, os participantes foram convidados a avaliar a oficina, com base em três critérios:

(1) Importância/contribuição da atividade: os participantes responderam que haviam visto algo similar, mas nunca tiveram a chance de participar. Logo, consideraram válida a experiência;

(2) Satisfação com a proposta: todos disseram que ficaram muito satisfeitos e que participariam de outras oficinas no futuro;

(3) Temas abordados: todos apontaram que gostaram dos temas tratados e sugeriram que eles fossem aprofundados em outras oficinas. 


\section{Considerações finais}

Este artigo apresentou uma proposta de oficina sobre o tema robótica sustentável, voltada para o ensino de Ciências nas séries finais do Ensino Fundamental, através da qual, pretendeu-se favorecer: (1) a autoaprendizagem, a interação e a colaboração entre os participantes; (2) a articulação e a integração da educação e da tecnologia de forma contextualizada; (3) o processo de construção de robôs e outros mecanismos feitos com componentes eletrônicos e da informática, sucata e peças de brinquedos.

Verificou-se que os os participantes consideraram válida a experiência e que participariam de outras oficinas no futuro. No tocante aos temas tratados, foi sugerido que eles fossem aprofundados em outras oficinas. Sendo assim, espera-se que com a continuidade do projeto por uma participante do grupo, que pleiteia admissão no mestrado, a construção de materiais didáticos mais complexos para a capacitação do grupo possa ser viabilizada.

\section{Agradecimentos}

Os autores agradecem aos professores participantes pelo apoio e comprometimento durante a oficina.

\section{Sustainable Robotics as a Strategy for Teaching Science}

\section{Abstract}

This article presents a sustainable robotics workshop aimed at teaching science in the final grades of elementary school, in which the participating teachers, besides being able to deepen their knowledge about the construction of robots and other mechanisms, were able to reflect on the themes of sustainability and environmental preservation. The workshop covered topics such as mechanics, movement, and energy. Because of the pandemic, this activity was conducted remotely. The results show that it is possible to make science classes more dynamic and promote various learning activities using resources available at school, such as scrap, recyclable, or reusable materials.

Keywords: Sustainable Robotics, Science Teaching, Workshop. 


\section{Notas}

1 Diz respeito à geração nascida entre meados dos anos 1990 até o início do ano 2010.

2 Trata-se da geração nascida a partir do ano 2010.

3 Na robótica livre, utiliza-se para a programação de robôs de baixo custo hardware e software que possibilitem que qualquer pessoa possa fazer as modificações necessárias e adequadas à sua realidade (ALMEIDA; SILVA; AMARAL, 2013). Segundo os autores, "um exemplo de microcontrolador, entre os existentes, é a placa de Arduino, criada na Itália em 2005” (p. 181).

4 "Na BNCC, competência é definida como a mobilização de conhecimentos (conceitos e procedimentos), habilidades (práticas,cognitivas e socioemocionais), atitudes e valores para resolver demandas complexas da vida cotidiana, do pleno exercício da cidadania e do mundo do trabalho" (BRASIL, 2018, p. 8).

5 Em substituição às disciplinas.

6 Através do Movimento Maker, as pessoas puderam se apropriar de ferramentas tecnológicas como, por exemplo, a placa Arduíno, impressoras 3D, cortadoras a laser e kits de robótica, para realizar a prototipação e fabricação de produtos, soluções e projetos. Sua origem se deu entre os anos de 1990 e a primeira década de 2000, mas foi após o lançamento da Revista Maker Movement, em 2005, e da Feira Maker, em 2006, que surgiu o Manifesto Maker e uma série de premissas como estas: faça você mesmo (do it yourself) ou faça com os outros (do it with others) (Gavassa et al. 2016).

7 Vídeos exibidos: ORIGEM DAS COISAS. A história da robótica: a origem dos robôs.14 de ago. de 2015 , 4m07s. Disponível em: https:/www.youtube.com/watch?v=5lh3OtqkLMU

SLIME SAM SAPECA. Faça o seu próprio transformer de papelão - Bumblebee. 8 de set. de 2019, 13m56s. Disponível em: https://www.youtube.com/watch?v=yftVAZtyx3E

FELLIPE, Leandro. Como fazer robô com sucata! Arte com Sucata! 7 ago. 2017, 8m16s. Disponível em: https://www.youtube.com/watch?v=mCLaLAgrCRo

\section{Referências}

ALMEIDA, Luma Cardoso Ferro de; SILVA, Jhonatan Sérgio Diniz Marques da; AMARAL, Haroldo José Costa do. Robótica Educacional: Uma Possibilidade para o Ensino e Aprendizagem. In: III Escola Regional de Informática de Pernambuco, 6-8 de novembro de 2013, Garanhuns, PE, Brasil, 2013.

BALDOW, Rodrigo; LEÃO, Marcelo Brito Carneiro. Robótica sustentável e aprendizagem colaborativa: contribuições no ensino de eletricidade e hidrostática. In: X Congreso Internacional Sobre Investigaciónen Didáctica De Las Ciencias, 5-8 de setembro de 2017, Sevilla, Espanha, 2017.

BOGARIM, Cintia Adriana Canteiro; LARREA, Andreia Alfonso; GHINOZZI, Glauder Guimaraes. Larpp Sustentável e seu Auxílio na Educação Ambiental nas Escolas e Comunidade de Ponta Porã. In: II Congresso Nacional de Educação, Campina Grande-PB, 2015.

BRASIL. Ministério da Educação (MEC). Secretaria de Educação Fundamental (SEF). Base Nacional Comum Curricular: Educação é a Base - Versão Final. Brasília: MEC/SEF, 2018.

BRITO, Robson Souto. A pesquisa brasileira em robótica pedagógica: um mapeamento sistemático com foco na educação básica. Dissertação de Mestrado, 103f.: il., Universidade Federal de Pernambuco, CE. Programa de Pós-graduação em Educação Matemática e Tecnológica, 2019. 
CELINSKI, Tatiana Montes; et al. Robótica Educativa: uma Proposta para o Reuso do Lixo Eletrônico em uma Atividade de Extensão Universitária. In: 4 Congresso Internacional de Educação, Pesquisa e Gestão, Curitiba-PR, 2012.

FUNDAÇÃO TELEFÔNICA VIVO. Eu, Robô! [Livro eletrônico]. Robótica sustentável de baixo custo. Organização Fundação Telefônica Vivo.1. ed. São Paulo: Instituto Conhecimento para Todos - IK4T, 2021. (Coleção de Tecnologias Digitais; 6)

FUNDAÇÃO TELEFÔNICA VIVO; INSTITUTO CONHECIMENTO PARA TODOS — IK4T; PROGRAMAÊ! Práticas pedagógicas: a cultura digital na resolução de problemas - 1. [Livro eletrônico]. São Paulo: Fundação Telefônica Vivo, 2020.

GAVASSA, Regina C. F. B.; MUNHOZ, Gislaine B.; MELLO, Luci Ferraz de; CAROLEI, Paula. Cultura maker, aprendizagem investigativa por desafios e resolucão de problemas na SME-SP (Brasil). In: FabLearn Brasil, 2016.

MEDEIROS, Luciano Frontino de; WUNSCH, Luana Priscila; BOTTENTUIT JUNIOR, João Batista. A robótica sustentável na educação: sucata e materiais elétricos como suporte para a formação do docente atual. Revista Cocar. Edição Especial, 5, 2019.

NASCIMENTO, João Batista do. Os recursos da robótica educacional. In: Mostra Nacional de Robótica (MNR), Itumbiara, Goiás, Brasil, 2015.

NUNES, Sergio da Costa; SANTOS, Renato Pires dos. O Construcionismo de Papert na criação de um objeto de aprendizagem e sua avaliação segundo a taxionomia de Bloom. In: Atas do IX Encontro Nacional de Pesquisa em Educação em Ciências - IX ENPEC, Águas de Lindóia, SP, Brasil, 10 a 14 de novembro de 2013.

PAPERT, Seymour. A máquina das crianças: repensando a escola na era da informática. Trad. Sandra Costa. Porto Alegre: Artmed, 2007.

PAPERT, Seymour. LOGO: Computadores e Educação. Trad. Afira V. Ripper. São Paulo: Brasiliense, 1986.

RAABE, André Luís Alice; BOMBASAR, James Roberto. Robótica Educacional na Educação Básica Pública Brasileira. Relatório de pesquisa, 2018.

REVISTA NOVA ESCOLA. Robótica sem usar o computador. Por: Beatriz Santomauro, Nova Escola, Beatriz Vichessi, 2008. https://novaescola.org.br/conteudo/1192/robotica-sem-usar-o-computador.

SILVA, João Batista da; et al. Cultura Maker e Robótica Sustentável no Ensino de Ciências: Um Relato de Experiência com Alunos do Ensino Fundamental. In: Anais do V Congresso sobre Tecnologias na Educação, Porto Alegre: SBC, 2020.

TOLEDO, Priscilla Bassitt Ferreira. O comportamento da Geração Z e a influência nas atitudes dos professores. In: Simpósio de Excelência em Gestão e Tecnologia. IX SEGeT, 2012. 